\title{
Prevalence of overweight and obesity in elderly people from Vitória-ES, Brazil
}

\author{
Prevalência de sobrepeso e obesidade \\ em idosos da cidade de Vitória-ES, Brasil
}

Fabíola Bof de Andrade ${ }^{1}$

Arnaldo de França Caldas Junior ${ }^{2}$

Pedro Makumbundu Kitoko ${ }^{3}$

Jose Edmilson Mazza Batista ${ }^{2}$

Tania Bof de Andrade ${ }^{4}$

${ }^{1}$ Departamento de Epidemiologia, Faculdade de Saúde Pública,

Universidade de São Paulo. Av. Dr. Arnaldo 715, Consolação. 01246-904 São Paulo SP.

fabiolabof@yahoo.com.br

${ }^{2}$ Universidade Federal de

Pernambuco

${ }^{3}$ Conselho de Segurança

Alimentar e Nutricional do

Estado do Espírito Santo

${ }^{4}$ Petrobras
Abstract The scope of this study was to estimate the prevalence of overweight and obesity and its association with socio-economic status in a sample of non-institutionalized elderly people from Vitória-ES, Brazil. This was a cross-sectional survey with a sample of 882 elderly people aged 60 and over. Obesity and overweight were assessed using the body mass index (BMI) and waist circumference (WC). All subjects answered a personal and socio-demographic questionnaire in relation to age, gender, marital status, physical activity, number of children, chronic diseases and smoking. Associations between categorical variables were tested using chi-square analysis with a $5 \%$ significance level. The prevalence of overweight and obesity was high $(41.8 \%$ and $23.4 \%$, respectively) and $50.7 \%$ of the elderly had a substantially increased waist circumference. About $4.3 \%$ of the individuals had diabetes, $50.4 \%$ had hypertension and $14.9 \%$ were found to have both diseases. It was observed that both the BMI and $W C$ were significant associated $(p<0.05)$ with sex, marital status, the presence of diseases and with cigarette smoking.

Key words Nutritional status, Elderly people, Obesity, Overweight
Resumo O objetivo deste estudo foi avaliar a prevalência de sobrepeso e de obesidade associados a fatores socioeconômicos, em uma amostra de idosos não institucionalizados de Vitória-ES, Brasil. Foi realizado um estudo transversal com uma amostra de 882 idosos com 60 anos ou mais. Estes parâmetros foram avaliados por meio do indice de massa corporal (IMC) e da circunferência da cintura (CC). Todos os participantes responderam a um questionário de dados pessoais e sociodemográficos em relação à idade, sexo, grau de instrução, estado civil, atividade física, número de filhos, doenças crônicas e tabagismo. Associações entre as variáveis categóricas foram testadas utilizando o teste qui-quadrado com um nivel de significância $5 \%$. Observou-se que prevalência de sobrepeso e obesidade de acordo com o IMC foi alta $(41,8 \%$ e $23,4 \%$, respectivamente) e $50,7 \%$ dos idosos apresentaram um substancial aumento da circunferencia abdominal. Verificou-se que 4,3\% dos indivíduos eram diabéticos, 50,4\% hipertensos e 14,9\% apresentaram ambas as doenças. Observou-se que tanto o IMC como a CC foram significativamente associados $(p<0,05)$ com o sexo, estado civil, presença de doenças e tabagismo.

Palavras-chave Estado nutricional, Idoso, Obesidade, Sobrepeso 


\section{Introduction}

The improvement in basic sanitation and health care during the last decades enabled a significant increase in life expectancy and, therefore, in the number of elderly people throughout the world. Today, the proportion of elderly is growing faster than the proportion of children and in the next 20 years the population of elderly in Brazil might exceed 30 million people and should represent nearly $13 \%$ of the population at the end of this period $^{1}$, including the country among the ten with the largest population of older persons in the world ${ }^{2}$.

This demographic transition has been followed by a change in the epidemiological profile of the population. There is a large number of evidence ${ }^{3-7}$ indicating an increased frequency of overweight and obesity worldwide which are among the risk factors for chronic diseases such as diabetes mellitus, hypertension and coronary heart disease. Despite this fact the obesity and overweight among elderly people is still inadequately documented ${ }^{8-10}$, especially in developing countries ${ }^{2,11}$

Overweight and obesity are a reflection of the combination of a variety of factors including a range of sociodemographic variables ${ }^{12-14}$ witch differs among regions, thereby influencing the prevalence of these diseases. According to the existing evidence, the Body Mass Index is greater in women than in $\operatorname{men}^{15,16}$, its distribution by age shifts to the left in elderly people ${ }^{17}$ and it is related to the educational level ${ }^{3,10}$ but there are still a controversy in relation to the direction of these association within the schooling groups. Some studies indicated a higher prevalence in higher income and educated groups ${ }^{13,16}$ while others found a negative association between the risk of being obese or overweight and educational level ${ }^{3}$. Bovet et al. ${ }^{18}$ observed that overweight was related with both occupation and education and the association was direct in men and inverse in women. In a view of this, the different associations of overweight and obesity with gender and SES emphasize the need to better understand the role of these independent variables in the nutritional status in order to develop appropriate health policy. Thus, the aim of this study was to estimate the prevalence of overweight and obesity and the association between these conditions and the socioeconomic status, in a sample of Brazilian non-institutionalized elderly people from Vitória-ES, Brazil.

\section{Methods}

This study is part of a cross-sectional study of oral health and nutritional status in non-institutionalized elderly people that was carried out in 2006. The sample comprised elderly people aged 60 and over. Participants were randomly selected from the Family Health Programme and from the Community Agents Health Programme in the city of Vitória-ES, Brazil. The sampling was made by clusters in three stages: in the first stage the districts were selected, in the second, the microareas and in the third stage, the elderly. The individuals who were physically (e.g. bedridden patients, wheelchair subjects and those not able to stand up) and/or mentally unable to undergo the examinations or answer the questionnaires were not considered in the sampling procedure. In order to estimate de proportion of elderly with overweight/obesity and an increased waist circumference the sample size was determined considering: the total number of non-institutionalized elderly people in the city of Vitória (31.177), a $3.5 \%$ error, $95 \%$ confidence level, a $60.0 \%$ and $72.0 \%$ expected prevalence of general overweight and increase waist circumference, respectively, which were found in a previous pilot study. Thus, 735 individuals were required but a $20 \%$ was added to this number to compensate for refusals, adding up to a total sample of 882 participants.

This project was approved by the Ethics in Research Commission of the University of Pernambuco and all the subjects signed an informed consent form immediately before the interview.

Trained staff conducted a face-to-face interview in the participants' homes and obtained information on demographic, socioeconomic and health status with focus on hypertension and diabetes mellitus, tobacco use and physical activity. Regular physical activity was defined as at least 30 minutes of moderate-intensity physical activity 3 times or more per week. With regard to the chronic diseases, subjects were considered as hypertensive or diabetics if they reported current use of anti-hypertensive or hypoglycemic agents.

Anthropometric measurements included weight, height and waist circumference (WC). Body Mass Index (BMI) was calculated as body weight divided by the square of the height in meters and the cut-offs set were those established by World Health Organization ${ }^{11}$ as follows: underweight $(<18.5)$, normal range (18.5-24.99), overweight (25-29.99) and obese ( 330$)$. Height was measured with a portable stadiometer, participants being measured barefoot and with the head hor- 
izontal in the Frankfurt plane. Weight was measured to the nearest 100 grams using a digital personal scale. Individuals were asked to stand still in centre of the platform, with body weight distributed between both feet. All participants wore light indoor clothes and were barefoot.

Waist circumference was used as a measure of abdominal adiposity. WC was taken midway between the lowest rib and iliac crest using a flexible tape applied directly to uncover skin at the end of normal expiration and was measured to the nearest millimeter. Men with WC $<94$, 94101.9 and ${ }^{3} 102 \mathrm{~cm}$ were classified as normal, increased and substantially increased WC, respectively, while women were classified on the same categories on the basis of WC $<80,80-87.9$ and $388 \mathrm{~cm}$. These cut-off values were established according to the World Health Organization ${ }^{14}$.

The statistical analysis included descriptive and inferential analyses, using a $5 \%$ significance level. Associations between categorical variables were tested using chi-square analysis. Data was tabulated using Epi Info 6.04 and was converted for analysis by the SPSS version 11.0 software.

\section{Results}

A sample of 833 participants completed the study, 49 individuals $(5.6 \%)$ were not at home, after at least three visits, or refused to complete the study for unknown reasons. There was a large percentage of females $(67.6 \%)$. Age ranged from 60 to 96 years (mean, 70.0 median), with $46.5 \%$ of the respondents in the 60 to 69-year-old group. About $43.4 \%$ of the individuals were earning the minimum wage (US\$169/month), 30.1\% from 2 to 5 times the minimum wage (US\$338$845 /$ month) and $11.1 \% 5$ or more times the minimum wage. The results showed that in the overall sample $4.3 \%$ had diabetes, $50.4 \%$ hypertension and $14.9 \%$ had both diseases.

It was observed that the mean BMI was 27.05 (SD 4.95) and the mean WC was $93.11 \mathrm{~cm}$ (SD 12.19). The prevalence of overweight and obesity based on BMI according to socioeconomic status (SES), presence of disease and physical activity are shown in Table 1. From this table it can be seen that the overall prevalence of overweight/ obesity was $65.2 \%$. It was observed that there were significant difference between BMI and sex $(\mathrm{p}<0.05)$. Women had a higher prevalence of obesity than man and an inverse pattern was found for overweight. Neither educational level nor physical activity were associated with BMI $(\mathrm{p}>0,05)$. With regard to marital status, it was found that overweight was the most prevalent within all groups and the single subjects were the ones with the lowest prevalence of overweight and obesity.

In relation to the WC, most of the elders $(50.7 \%)$ had a substantially increased abdominal adiposity ( $W C \geq 102$ and $\geq 88 \mathrm{~cm}$ for men and women, respectively). About $26.1 \%$ had an increased risk and $23.2 \%$ had a normal WC. The association between WC, SES, physical activity and presence of disease are displayed in Table 2.

\section{Discussion}

From a review of the literature, it can be seen that there is still few information about the frequency of overweight and obesity in elderly people, specifically the ones from population-based studies. From this study, it was observed that there was no risk of underweight among the individuals. Studies have shown an increase of underweight with aging, however, the prevalence is very small and in most cases it does not includes a significant proportion of the population ${ }^{19-21}$ which is in accordance with the findings of this study. About $2.4 \%$ of the elderly had a BMI below 18.5 , though this low prevalence is not relevant because it is included within the 3 to $5 \%$ of the fraction of the population that are biologically thin ${ }^{11}$.

Unfortunately, the prevalence of overweight largely overcomes the underweight and/or normal range people, thereby demonstrating that this epidemiologic context should be evaluated carefully when considering the elderly population, especially due to their close relationship with the development of chronic diseases. In the present study, $41.8 \%$ and $23.4 \%$ of the non-institutionalized elderly were overweight and obesity, respectively, and $50.7 \%$ of the individuals had a substantially increased WC corroborating the worldwide concerning about a global epidemic ${ }^{22,23}$. Our results are also similar to the ones described in the last epidemiological survey carried out in $\mathrm{Brazil}^{20}$.

In relation to gender, it was found a significant association between sex and both the obesity indicators. Women had a higher prevalence of substantially increased WC ( $62.7 \%$ vs $25.6 \%)$ and obesity ( $29.7 \%$ vs 10.4$)$, on the other hand more men had an increased abdominal adiposity $(29.6 \%$ vs $24.4 \%)$ and were more overweight ( 50.0 vs 37.8 ) than women. This trend is in accordance with the results from other community-based surveys ${ }^{3,6,24,25}$ and, particularly, the ones 
Table 1. Distribution of BMI according to the socio-economic status (SES), presence of disease, smoking and physical activity.

\begin{tabular}{|c|c|c|c|c|c|c|c|c|c|c|c|}
\hline & \multicolumn{2}{|c|}{ Underweight } & \multicolumn{2}{|c|}{ Normal } & \multicolumn{2}{|c|}{ Overweight } & \multicolumn{2}{|c|}{ Obese } & \multicolumn{2}{|c|}{ Total } & \multirow[t]{2}{*}{ p-value } \\
\hline & $\mathrm{N}$ & $\%$ & $\mathrm{~N}$ & $\%$ & $\mathrm{~N}$ & $\%$ & $\mathrm{~N}$ & $\%$ & $\mathrm{~N}$ & $\%$ & \\
\hline Total group & 17 & 2.0 & 273 & 32.8 & 348 & 41.8 & 195 & 23.4 & 833 & 100.0 & \\
\hline $\operatorname{Sex}^{*}$ & & & & & & & & & & & $\mathrm{p}<0.001$ \\
\hline Male & 4 & 1.5 & 103 & 38.1 & 135 & 50.0 & 28 & 10.4 & 270 & 100.0 & \\
\hline Female & 13 & 2.3 & 170 & 30.2 & 213 & 37.8 & 167 & 29.7 & 563 & 100.0 & \\
\hline $\operatorname{Age}^{*}$ & & & & & & & & & & & $\mathrm{p}=0.047$ \\
\hline $60-69$ years & 9 & 2.3 & 113 & 29.2 & 162 & 41.9 & 103 & 26.6 & 387 & 100.0 & \\
\hline $70-79$ years & 3 & 1.0 & 104 & 33.9 & 130 & 42.3 & 70 & 22.8 & 307 & 100.0 & \\
\hline$\geq 80$ years & 5 & 3.6 & 56 & 40.3 & 56 & 40.3 & 22 & 15.8 & 139 & 100.0 & \\
\hline Educational level ${ }^{\star}$ & & & & & & & & & & & $\mathrm{p}=0.131$ \\
\hline Low & 14 & 2.2 & 193 & 30.7 & 272 & 43.2 & 150 & 23.8 & 629 & 100.0 & \\
\hline Mid & 1 & 0.6 & 64 & 39.5 & 64 & 39.5 & 33 & 20.4 & 162 & 100.0 & \\
\hline High & 2 & 4.9 & 16 & 39.0 & 12 & 29.3 & 11 & 26.8 & 41 & 100.0 & \\
\hline Marital status ${ }^{*}$ & & & & & & & & & & & $\mathrm{p}=0.040$ \\
\hline Married & 6 & 1.5 & 124 & 31.0 & 185 & 46.3 & 85 & 21.3 & 400 & 100.0 & \\
\hline Single/divorced & 6 & 3.9 & 58 & 37.9 & 59 & 38.6 & 30 & 19.6 & 153 & 100.0 & \\
\hline Widowed & 5 & 1.8 & 90 & 32.4 & 104 & 37.4 & 79 & 28.4 & 278 & 100.0 & \\
\hline No of children ${ }^{*}$ & & & & & & & & & & & $\mathrm{p}<0.005$ \\
\hline 0 & 5 & 8.2 & 29 & 47.5 & 16 & 26.2 & 11 & 18.0 & 61 & 100.0 & \\
\hline $1-2$ & 4 & 2.1 & 60 & 31.4 & 77 & 40.3 & 50 & 26.2 & 191 & 100.0 & \\
\hline $3-4$ & 5 & 2.0 & 75 & 30.2 & 111 & 44.8 & 57 & 23.0 & 248 & 100.0 & \\
\hline$\geq 5$ & 3 & 0.9 & 109 & 32.7 & 144 & 43.2 & 77 & 23.1 & 333 & 100.0 & \\
\hline Disease $^{*}$ & & & & & & & & & & & $\mathrm{p}<0.001$ \\
\hline Diabetes & 1 & 2.8 & 11 & 30.6 & 18 & 50.0 & 6 & 16.7 & 36 & 100.0 & \\
\hline Hypertension & 6 & 1.4 & 115 & 27.4 & 183 & 43.7 & 115 & 27.4 & 419 & 100.0 & \\
\hline $\begin{array}{l}\text { Diabetes/ } \\
\text { Hypertension }\end{array}$ & - & - & 32 & 25.8 & 55 & 44.4 & 37 & 29.8 & 124 & 100.0 & \\
\hline Others & 6 & 4.4 & 59 & 43.4 & 51 & 37.5 & 20 & 14.7 & 136 & 100.0 & \\
\hline None & 4 & 3.4 & 55 & 47.4 & 40 & 34.5 & 17 & 14.7 & 116 & 100.0 & \\
\hline Physical activity* & & & & & & & & & & & $\mathrm{p}=0.397$ \\
\hline Yes & 2 & 1.0 & 72 & 34.3 & 93 & 44.3 & 43 & 20.5 & 210 & 100.0 & \\
\hline No & 14 & 2.3 & 194 & 32.2 & 249 & 41.3 & 146 & 24.2 & 603 & 100.0 & \\
\hline Smoking* & & & & & & & & & & & $\mathrm{p}<0.001$ \\
\hline Yes & 8 & 11.1 & 37 & 50.7 & 21 & 28.8 & 7 & 9.6 & 73 & 100.0 & \\
\hline No & 9 & 1.2 & 232 & 30.9 & 324 & 43.1 & 187 & 24.9 & 752 & 100.0 & \\
\hline
\end{tabular}

${ }^{*}$ Difference in the number of total individual is due to missing data.

carried out in Brazil were women had a higher proportion of excessive BMI than men ${ }^{26}$ and the mean BMI was also significantly lower for males than females ${ }^{12,13,15}$. According to the literature this association might occur due to the fact that men have more lean mass in comparison to women while the latter have a greater tendency to accumulate fat ${ }^{9}$.

In analyzing the relationship between age and body fat distribution, studies have shown that overweight and obesity increases with age until about 70 years of age and then decline ${ }^{5}$ and the reduction in lean mass together with weight loss that occurs with aging has also been pointed out as a reason for the decrease in $\mathrm{BMI}^{11}$. In addition, according to some authors ${ }^{9}$ the selective survival of health elderly could play an important role in this relation, thereby accounting for the lower prevalence of obesity among the very old people. Barreto et al. ${ }^{13}$ found a significant decrease in the mean BMI with age but in relation to obesity this decrease was only statistically significant among women. Like other surveys ${ }^{12,27}$ in the present study the results showed a significant association between BMI and age ( $\mathrm{p}=0.047)$. From Table 1 it can be seen a liner trend in which 
Table 2. Distribution of WC according to the socio-economic status (SES), presence of disease, smoking and physical activity.

\begin{tabular}{|c|c|c|c|c|c|c|c|c|c|}
\hline & \multicolumn{2}{|c|}{ Increased } & \multicolumn{2}{|c|}{$\begin{array}{l}\text { Substantially } \\
\text { increased }\end{array}$} & \multicolumn{2}{|c|}{ Normal } & \multicolumn{2}{|c|}{ Total } & \multirow[t]{2}{*}{ p-value } \\
\hline & $\mathbf{N}$ & $\%$ & $\mathrm{~N}$ & $\%$ & $\mathrm{~N}$ & $\%$ & $\mathbf{N}$ & $\%$ & \\
\hline Total group & 217 & 26.1 & 421 & 50.7 & 193 & 23.2 & 831 & 100.0 & \\
\hline $\operatorname{Sex}^{\star}$ & & & & & & & & & $\mathrm{p}=0.000$ \\
\hline Male & 80 & 29.6 & 69 & 25.6 & 121 & 44.8 & 270 & 100.0 & \\
\hline Female & 137 & 24.4 & 352 & 62.7 & 72 & 12.8 & 561 & 100.0 & \\
\hline $\operatorname{Age}^{*}$ & & & & & & & & & $\mathrm{p}=0.803$ \\
\hline $60-69$ years & 107 & 27.7 & 187 & 48.4 & 92 & 23.8 & 386 & 100.0 & \\
\hline $70-79$ years & 75 & 24.4 & 163 & 53.1 & 69 & 22.5 & 307 & 100.0 & \\
\hline$\geq 80$ years & 35 & 25.4 & 71 & 51.4 & 32 & 23.2 & 138 & 100.0 & \\
\hline Educational level $^{*}$ & & & & & & & & & $\mathrm{p}=0,013$ \\
\hline Low & 148 & 23.6 & 339 & 54.1 & 140 & 22.3 & 627 & 100.0 & \\
\hline Mid & 53 & 32.7 & 67 & 41.4 & 42 & 25.9 & 162 & 100.0 & \\
\hline High & 15 & 36.6 & 15 & 36.6 & 11 & 26.8 & 41 & 100.0 & \\
\hline Marital status ${ }^{*}$ & & & & & & & & & $\mathrm{p}=0.001$ \\
\hline Married & 112 & 28.1 & 180 & 45.2 & 106 & 26.6 & 398 & 100.0 & \\
\hline Single/divorced & 40 & 26.1 & 72 & 47.1 & 41 & 26.8 & 153 & 100.0 & \\
\hline Widowed & 64 & 23.0 & 168 & 60.4 & 46 & 16.5 & 278 & 100.0 & \\
\hline No of children ${ }^{*}$ & & & & & & & & & $\mathrm{p}=0.220$ \\
\hline 0 & 16 & 26.2 & 23 & 37.7 & 22 & 36.1 & 61 & 100.0 & \\
\hline $1-2$ & 55 & 28.8 & 95 & 49.7 & 41 & 21.5 & 191 & 100.0 & \\
\hline $3-4$ & 65 & 26.4 & 125 & 50.8 & 56 & 22.8 & 246 & 100.0 & \\
\hline$\geq 5$ & 81 & 24.3 & 178 & 53.5 & 74 & 22.2 & 333 & 100.0 & \\
\hline Disease $^{*}$ & & & & & & & & & $\mathrm{p}=0.000$ \\
\hline Diabetes & 6 & 2.8 & 21 & 5.0 & 9 & 4.7 & 36 & 4.3 & \\
\hline Hypertension & 105 & 48.6 & 238 & 56.5 & 74 & 38.5 & 417 & 50.3 & \\
\hline Diabetes/Hypertension & 31 & 14.4 & 70 & 16.6 & 22 & 11.5 & 123 & 14.8 & \\
\hline Others & 38 & 17.6 & 58 & 13.8 & 41 & 21.4 & 137 & 16.5 & \\
\hline None & 36 & 16.7 & 34 & 8.1 & 46 & 24.0 & 116 & 14.0 & \\
\hline Total group & 216 & 100.0 & 421 & 100.0 & 192 & 100.0 & 829 & 100.0 & \\
\hline Physical activity ${ }^{*}$ & & & & & & & & & $\mathrm{p}=0,03$ \\
\hline Yes & 65 & 31.0 & 90 & 42.9 & 55 & 26.1 & 210 & 100.0 & \\
\hline No & 148 & 24.6 & 321 & 53.4 & 132 & 22.0 & 601 & 100.0 & \\
\hline Smoking* & & & & & & & & & $\mathrm{p}=0.000$ \\
\hline Yes & 20 & 27.4 & 16 & 21.9 & 37 & 50.7 & 73 & 100.0 & \\
\hline No & 193 & 25.7 & 402 & 53.6 & 155 & 20.7 & 750 & 100.0 & \\
\hline
\end{tabular}

${ }^{*}$ Difference in the number of total individual is due to missing data.

obesity decreases within the age groups and the lower prevalence is observed among those with 80 years or older. With regard to the overweight, it can be seen a slightly increase from 60-69 year of age to 70-79 years and then it decreases again. The same was not true in relation to the WC ( $p>0,05)$, but it is noteworthy that the oldest people had the highest prevalence of increased and substantially increased WC.

Studies have demonstrated significant correlations between SES and health indicators ${ }^{3,28}$. $\mathrm{WHO}^{14}$ reported that the distribution of BMI varies significantly according to the stage of de- velopment reached by societies, and there is a trend of decrease in the number of people with low BMI and an increase in the overweight and obesity, according to the improvement of socioeconomic conditions. Kamadjeu et al..$^{29}$ found that the likelihood of overweight or obesity was about 2 and 3.5 fold for adult people with 7-14 years and $>14$ years of education, respectively, corroborating the findings from Barreto et al. ${ }^{13}$ who observed that obesity was more common among subjects with higher educational levels. Different from those findings Bowie et al. ${ }^{3}$ reported that educational level was inversely asso- 
ciated with the risk of being overweight or obese for all Mexican American investigated with $\geq 15$ years of age. Furthermore, Sulander \& Uutela ${ }^{10}$ found that, among elderly people, those with lower educational level had a higher risk of obesity confirming the results of other surveys carried out with older people ${ }^{27,30}$. In the present study, it was observed a significant association between educational level and WC, subjects with higher educational level had the lowest prevalence of increased abdominal adiposity. This relation may be justified by the fact that high educated people might be more aware about the risks related to a increased abdominal adiposity and they also might be more worried about their appearance which is also related to culture concerns and social behaviors, but further studies is needed for better understating of this relation. With regard to BMI, the present findings showed no difference between BMI and the educational level.

In this study it was observed, a high prevalence of both hypertension and diabetes mellitus among non-institutionalized elderly and these diseases were significant associated with BMI and WC, thereby supporting the results described previously by other authors ${ }^{31}$. Zindah et al. ${ }^{32}$ found that obesity was significantly associated with diabetes, high blood pressure and high cholesterol. According to these authors, compared with adults of normal weight, obese adults had OR of 3.27 (95\% CI, 1.58-6.76) for diabetes and OR of 3.69 (95\% CI, 2.13-6.39) for high blood pressure. Grievink et al. ${ }^{24}$ found that WC was strongest associated with a higher prevalence of hypertension and diabetes mellitus. This tendency was verified in this study in which most $(56.5 \%)$ of the subjects with a substantially increased WC were hypertensive. Moreover, obesity was also higher among those with hypertension (Table 1) highlighting the increased risk for multiple health problems such as the ones related to cardiovascular diseases.

Both the development of obesity and the increased risk of chronic diseases are related with physical inactivity and sedentary behaviors ${ }^{3,14,32,33}$. Martýnez et al. ${ }^{34}$ observed that a low participation in sport activities and a lack of interest in being involved in physical activity were all significant predictors of obesity. Our results are consistent with this concept, but only the abdominal adiposity was found to be related to physical activity with the majority of the physical inactive elderly showing a substantially increased WC. In relation to physical activities, it is important to mention that there are different method- ologies applied to measure this variable with makes it difficult to establish valid comparisons between studies.

Finally, it was found a significant association between cigarette smoking and the prevalence of overweight and obesity. It was observed that the prevalence was higher among nonsmokers corroborating the findings from already published data which found that smoking is negatively associated to obesity ${ }^{11,34,35}$. Bovet et al..$^{18}$ found that overweight and obesity were directly associated with past smoking and inversely with current smoking. According to the literature ${ }^{34,35}$, smokers tend to be thinness than they would otherwise because it reduces appetite and stimulate the body's metabolic rate ${ }^{11}$.

There are many ways of measuring the overweight and obesity, though most of them require the use of high technology and expensive instruments making the development of epidemiological surveys a difficulty strategy, particularly when it comes to assessing the nutritional status in developing countries where financial resources for researches are still scarce. Thus, the BMI and WC measurement remains a useful, simple, noninvasive and low cost toll ${ }^{36,37}$. The results from this study are in agreement with the existing evidence, indicating that overweight and obesity are associated to a number of SES and behavioral variables. However, it is important to highlight the fact that that this study was limited by its cross-sectional design, which lacks sufficient power to establish a cause-effect relationship, thereby demonstrating the need to carry out longitudinal studies.

Based on the observations described herein it was concluded that the prevalence of overweight and obesity was high among elderly and it was associated with the socioeconomic status, presence of diabetes and/or hypertension and also with cigarette smoking. In a view of this, it is important to point out that obesity should be tackled as a major public health problem, highlighting the need for more researches, particularly in developing countries, in order provide new approaches in the direction of health promotion, including health eating and physical activities, not only for the elderly population but for all ages groups to give them a chance of a healthy aging, because the health status of our today's elderly is as a reflex of the care received throughout life. Furthermore, it is worthwhile to mention that the well being of this fast growing segment of the population also represents a political e economical issue and should not be overlooked. 


\section{Collaboration}

FB Andrade, AF Caldas Junior, PM Kitoko worked on the elaboration of the research project, data collection and analysis and on the conception and writing of this paper. TB Andrade worked on the data collection and on the conception and writing of this paper. JEM Batista worked on the data analysis/interpretation and on the conception of this paper.

\section{Acknowledgements}

This study was sponsored by the Brazilian $\mathrm{Na}$ tional Research Council - CNPq and by the city hall of Vitória-ES, Brazil.

\section{Referências}

1. Instituto Brasileiro de Geografia e Estatística (IBGE). Perfil dos Idosos responsáveis pelos domicílios no Brasil 2000. Rio de Janeiro: IBGE; 2002.

2. World Health Organization (WHO). Keep fit for life. Meeting the nutritional needs of older persons. Geneva: World Health Organization (WHO); 2002.

3. Bowie JV, Juon HS, Cho J, Rodriguez EM. Factors associated with overweight and obesity among Mexican Americans and Central Americans: results from the 2001 California Health Interview Survey. Prev Chronic Dis 2007; 4(1):1-17.

4. Rguibi M, Belahsen R. Prevalence of obesity in Morocco. Obes Rev 2007; 8(1):11-13.

5. Schokker DF, Visscher TL, Nooyens AC, van Baak MA, Seidell JC. Prevalence of overweight and obesity in the Netherlands. Obes Rev 2007; 8(2):101-108.

6. do Carmo I, dos Santos O, Camolas J, Vieira J, Carreira M, Medina L, Reis L, Galvão-Teles A. Prevalence of obesity in Portugal. Obes Rev 2006; 7(3):233237.

7. Ford ES, Mokdad AH, Giles WH. Trends in waist circumference among U.S. adults. Obes Res 2003; 11(10):1223-1231.

8. Marques APO, Arruda IKG, Espírito Santo ACG Raposo MCF, Guerra MD, Sales TF. Prevalência de obesidade e fatores associados em mulheres idosas. Arq Bras Endocrinol Metab 2005; 49(3):441-448.

9. Gutiérrez-Fisac JL, López E, Banegas JR, Graciani A, Rodríguez-Artalejo F. Prevalence of overweight and obesity in elderly people in Spain. Obes Res 2004; 12(4):710-715.

10. Sulander TT, Uutela AK. Obesity and education: recent trends and disparities among 65- to 84-yearold men and women in Finland. Prev Med 2007; 45(2-3):153-156.

11. World Health Organization (WHO). Physical status: the use and interpretation of anthropometry. Report of a WHO Expert Committee. Technical Report Series No 854. Geneva: World Health Organization (WHO); 1995.

12. Barbosa AR, Souza JM, Lebrão ML, Laurenti R, Marucci MFN. Anthropometry of elderly residents in the city of São Paulo, Brazil. Cad Saude Publica 2005; 21(6):1929-1938.

13. Barreto SM, Passos VM, Lima-Costa MF. Obesity and underweight among Brazilian elderly: the Bambuí Health and Aging Study. Cad Saude Publica 2003; 19(2):605-612.

14. World Health Organization (WHO). Obesity: preventing and managing the global epidemic: report of a WHO consultation. WHO technical report series no 894. Geneva. World Health Organization (WHO); 2000.

15. Mastroeni MF, Erzinger GS, Mastroeni SSBS, Silva NN, Marucci MFN. Demographic profile of the elderly in the city of Joinville, Santa Catarina: a household survey. Rev Bras Epidemiol 2007; 10(2):190-201.

16. Wang Y, Chen HJ, Shaikh S, Mathur P. Is obesity becoming a public health problem in India? Examine the shift from under- to overnutrition problems over time. Obes Rev 2009; 10(4):456-474. 
17. World Health Organization (WHO). Physical status: the use and interpretation of anthropometry. Report of a WHO Expert Committee. Technical Report Series No 854. Geneva. World Health Organization (WHO); 1995.

18. Bovet P, Chiolero A, Shamlaye C, Paccaud F. Prevalence of overweight in the Seychelles: 15 year trends and association with socio-economic status. Obes Rev 2008; 9(6):511-517.

19. Tavares EL, Anjos LA. Perfil antropométrico da população idosa brasileira. Resultados da Pesquisa Nacional sobre saúde e nutrição. Cad Saude Publ 1999; 15(4):759-768.

20. Instituto Brasileiro de Geografia e Estatística (IBGE). Pesquisa de orçamentos familiares 2002-2003. Análise da disponibilidade domiciliar de alimentos e estado nutricional no Brasil. Rio de Janeiro: Instituto Brasileiro de Geografia e Estatística (IBGE); 2004.

21. Huang YC, Wueng SL, Ou CC, Cheng $\mathrm{CH}$, Su KH. Nutritional status of functionally dependent and nonfunctionally dependent elderly in Taiwan. $J$ Am Coll Nutr 2001; 20(2):135-142.

22. Padez C. Trends in overweight and obesity in Portuguese conscripts from 1986 to 2000 in relation to place of residence and educational level. Public Health 2006; 120(10):946-952.

23. Sánchez-Castillo CP, Velásquez-Monroy O, LaraEsqueda A, Berber A, Sepulveda J, Tapia-Conyer R, James WP. Diabetes and hypertension increases in a society with abdominal obesity: results of the Mexican National Health Survey 2000. Public Health Nutr 2005; 8(1):53-60.

24. Grievink L, Alberts JF, O’Niel J, Gerstenbluth I. Waist circumference as a measurement of obesity in the Netherlands Antilles; associations with hypertension and diabetes mellitus. Eur J Clin Nutr 2004; 58(8):1159-1165.

25. Kruger J, Ham SA, Prohaska TR. Behavioral risk factors associated with overweight and obesity among older adults: the 2005 National Health Interview Survey. Prev Chronic Dis 2009; 6(1):A14.

26. Menezes TN, Marucci Mde F. Trends in body fat and muscle mass among elderly individuals in Fortaleza, Ceará State, Brazil. Cad Saude Publica 2007; 23(12):2887-2895.

27. Kaplan MS, Huguet N, Newsom JT, McFarland BH, Lindsay J. Prevalence and correlates of overweight and obesity among older adults: findings from the Canadian National Population Health Survey. J Gerontol A Biol Sci Med Sci 2003; 58(11):1018-1030.

28. Szwarcwald CL, Bastos FI, Esteves MAP, Andrade CLT, Paez MS, Medici EV, Derrico M. Desigualdade de renda e situação de saúde: o caso do Rio de Janeiro. Cad Saude Publica 1999; 15(1):15-28.
29. Kamadjeu RM, Edwards R, Atanga JS, Kiawi EC, Unwin N, Mbanya JC. Anthropometry measures and prevalence of obesity in the urban adult population of Cameroon: an update from the Cameroon Burden of Diabetes Baseline Survey. BMC Public Health 2006; 13(6):228.

30. Sundquist K, Qvist J, Johansson SE, Sundquist J. Increasing trends of obesity in Sweden between 1996/ 97 and 2000/01. Int J Obes Relat Metab Disord 2004; 28(2):254-261.

31. Olinto MT, Nacul LC, Gigante DP, Costa JS, Menezes AM, Macedo S. Waist circumference as a determinant of hypertension and diabetes in Brazilian women: a population-based study. Public Health Nutr 2004; 7(5):629-635.

32. Zindah M, Belbeisi A, Walke H, Mokdad AH. Obesity and diabetes in Jordan: findings from the behavioral risk factor surveillance system, 2004. Prev Chronic Dis 2008; 5:A17.

33. Nicklas BJ, Cesari M, Penninx BW, Kritchevsky SB, Ding J, Newman A, Kitzman DW, Kanaya AM, Pahor M, Harris TB. Abdominal obesity is an independent risk factor for chronic heart failure in older people. J Am Geriatr Soc 2006; 54(3):413-420.

34. Martínez JA, Kearney JM, Kafatos A, Paquet S, Martínez-González MA. Variables independently associated with self-reported obesity in the European Union. Public Health Nutr 1999; 2(1a):125-133.

35. Yore MM, Fulton JE, Nelson DE, Kohl HW III. Cigarette smoking status and the association between media use and overweight and obesity. Am J Epidemiol 2007; 166(7):795-802

36. World Health Organization (WHO). Use and interpretation of anthropometric indicators of nutritional status. Bull World Health Organ 1986; 64(6):929941.

37. Bray GA. Classification and evaluation of the obesities. Med Clin North Am 1989; 73(1):161-184.

Apresentado em 17/10/2008

Aprovado em 29/04/2009

Versão final apresentada em 20/05/2009 